\title{
Kuwaiti Female Leaders' Perspectives: The Influence Of Culture On Their Leadership
}

Omaymah E. Al-Suwaihel, Colorado State University, USA

\begin{abstract}
This research revealed the interactions between the Kuwaiti culture, gender, and leadership from the perspective of five Kuwaiti female leaders. Within a qualitative design approach and narrative inquiry methodology, the researcher interviewed five Kuwaiti females who shared their stories of their personal and professional experiences about the interactions between culture, gender, and leadership. The analysis and interpretation of this research uncovered two key findings: 1) the influence of Kuwaiti culture on female leadership and 2) the commitment of these female leaders to have a positive impact on their culture. The development of female leadership within Kuwait represented a collaborative effort by all the country's female leaders. As this research showed, these female leaders took advantage of every opportunity to prove their capabilities as leaders who deserve to serve effectively beside male leaders. The research data included some recommendations that could provide significant support for the development of female leaders, not only in the State of Kuwait, but also in other countries that could benefit from such progress. In addition, this project included some implications for further research studies focused on issues related to the interactions between female leadership and cultural influences.
\end{abstract}

Keywords: Female leadership, Kuwait, culture influence, gender role, leader, Middle East, narrative inquiry

\section{INTRODUCTION}

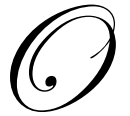

ver time, the concept of leadership has developed independently based on various research theories. In addition, Donald, Dale, and Sonya (2006) have suggested that effective leadership involves aspects such as self-awareness, organization of ongoing communication and reinforcement, a shared future vision, and some motivating action. Furthermore, leaders themselves, during this period, characterized various leadership styles in the respect that each leader had his or her own style that worked, each attained the organization's goals, and each satisfied the workers (Manning \& Haddock, 1989). Having an effective leadership style during this time meant leaders identified their goals and the organization's objectives, demonstrated productivity, provided open communication channels, and designed appropriate performance criteria that fit with the time, funding, quantity, and quality of the specified goals (1989).

The research literature discussed leadership as it relates to style and behaviors. For example, the literature suggested that particular behaviors leaders exhibit are effective in motivating those who report to them. Smith (2006) argued that leadership influences followers' thinking, attitudes, and behaviors. Yet leadership behaviors also vary according to each leader's particular reactions to situations, depending on gender, culture, knowledge, experiences, communication skills, and relationships, and those same elements shape leaders' behaviors. Some of these behaviors often are influenced by differing cultural expectations for men and women. Smith (2006) added that leadership behaviors are linked to two categories: task behaviors, which concentrate on attaining the organization's objectives (autocratic structure) and relationship behaviors, which are concerned with developing a healthy atmosphere where personnel feel more comfortable (democratic structure).

\section{LITERATURE REVIEW}

Several studies examined multiple leadership styles from different perspectives, and how gender influenced leadership styles; the studies showed various results. Some studies indicated differences with findings that supported 
various types of female leadership styles. For instance, Joyce (200five) found that the majority of female leaders tended to use more democratic than autocratic approaches of management, while Thompson (2002) stated that female leaders who used the democratic style were rare. In addition, from the college students' perspectives as future followers, they preferred to work with democratic leaders (Cellar, Sidle, Goudy, and O'Brien (2001).

Some researchers discussed the directive and the participative leadership styles and how leaders, followers, and organizations would benefit when these styles are implemented. There seem to be differences between women and men in terms of their leadership styles that sometimes predict a better fit for females or males. Furthermore, some research (Skinner, 2006) has indicated that female leaders tend to be more participative than directive in their leadership styles.

Generally, culture has had an impact upon leadership and gender roles, and every society has had its own definitions of effective leadership and its own distinct attitudes toward leaders. The culture has determined these attitudes (House, Javidan, Hanges, \& Dorfman, 2002). Lederach (199five) defined culture as "the shared knowledge and schemes created by a set of people for perceiving, interpreting, expressing, and responding to the social realities around them" (p. 9). He said that the shared knowledge and schemes were different in each culture, and that they influenced the expectations of leadership. The culture of Kuwait has been no exception.

Additionally, masculine and feminine orientations are related to cultures; but, in general, masculinity is more highly valued (Wiener, 200five). In cultures that value masculinity more highly, men dominate in relationships with women (200five). Some research validated the stereotypes that characterize masculine and feminine leadership; males were described more by aggressiveness, while female leadership was characterized more by assertiveness (Smith, 2006).

\section{Background}

Historically, most Kuwaiti females were housewives, responsible for taking care of their families while their spouses traveled for business (Tetreault, 2001). In the past century, and particularly in the past two decades, Kuwaiti females have improved their skills and, for example, risen to positions as ambassadors and to roles as educational administrators and business managers. They have also played a role in international conferences (e.g., UN conferences in Mexico City in 197five, in Copenhagen in 1980, and in Nairobi in 198five). In these positions, they have participated beside men and demonstrated the accomplishment of Kuwaiti females in organizations (AlMughni, 1993). Furthermore, the progress in democratization and social development in Kuwait has created opportunities for females to hold different organizational leadership roles in formal groups at the local, neighborhood, and national levels (Rizzo, 200five). Although the opportunity for women to participate in leadership positions has increased, the attitudes toward females in those leadership positions vary among the Kuwaiti people, depending on the cultural backgrounds of male leaders.

In 1999, the Emir of Kuwait, Sheikh Jaber Al-Ahmed Al-Sabah, took major steps to improve the political status of Kuwaiti females. For example, he established convincing agreements with government entities, including Parliament, to bridge the gap between the different viewpoints. Approximately 4 years later, Emir issued a royal decree granting Kuwaiti females equal rights (Al-Kazi, Lubna, Vital Voices). Kuwaiti females were granted the right to vote and to stand in Parliament on the $16^{\text {th }}$ of May, 200five (Central Intelligence Agency, 2008). They subsequently participated in elections for the first time in June 2006. In contrast, men had been eligible to vote since 1963 (Al-Mughni, 1993). In the June 2006 election, 28 female candidates ran for Parliament, but none of them had a chance to win (CNN Arabic, 2006). A year later, the first woman to hold a position in the Kuwaiti government was appointed as both Minister of Planning and Minister of Administrative Development (Freedom House, 2006). One year later, females were appointed to the posts of Minister of Communications, Minister of Health, and Minister of Education (People's Daily Online, 2007).

After years of struggle, the expansion of political participation by females has led to a new vision for the role of females in Kuwaiti society. But these changes have not been without controversy. The changes have been debated formally by government and elected officials in Parliament, and informally by Kuwaiti citizens at social gatherings and in the course of everyday conversations. The many aspects of Kuwaiti culture have influenced these 
formal and informal discussions. In other words, arguments about female leadership and the impact of culture on that leadership are enduring.

\section{PURPOSE OF THE STUDY}

The purpose of this study is to identify how Kuwait female leaders perceive the cultural influences on their personal and professional experiences in leadership positions. Thus, this study presents Kuwaiti female leaders' perspectives on the interactions of the Kuwaiti culture, gender, and leadership in governmental and nongovernmental organizations, and recounts their journeys as they have risen to higher leadership positions.

\section{RESEARCH QUESTIONS}

The present study sought answers to several sub-questions that support the central research question. The central question is: How do Kuwaiti female leaders experience the impact of culture on their leadership? The research sub-questions are: how do female leaders' culturally based personal experiences influence their leadership?; how do female leaders' based personal experiences influence their leadership?; how do female leaders' culturally based professional experiences influence their approach to leadership?; what new cultural experiences are female leaders gaining from their positions?.

\section{RESEARCH DESIGN}

I chose to use a qualitative research design to meet the study's purpose and answer the research questions in depth through the female leaders' experiences (Creswell, 200five). Qualitative research as an empirical strategy poses questions through interviews or observation of people's experiences for the purpose of understanding individual and group interactions in specific social contexts (Locke, Spirduso, \& Silverman, 2000). Therefore, the qualitative method is appropriate to show different perspectives (Creswell, 1998). In this study, I have presented participants' views about the interactions between their culture and their experiences that influenced their leadership, and I have discussed their different perspectives about these interactions.

\section{RESEARCH METHODOLOGY}

Research methodology for this study is narrative. Educational studies are an area of human experience in which the narrative approach is an effective way to represent participants' experiences (Clandinin \& Connelly, 2000). The narrative approach was designed for the researcher to collect and analyze data by representing connections between events (Lieblich, Tuval-Mashiach, \& Zilber, 1998). Data in the narrative approach can be a life or personal story collected by interview, observations, or library materials (1998). However, the narrative approach represents more than simply the telling of a story. Additionally, the narrative approach assesses the participants' responses individually, and emphasizes their narratives within specific social, cultural, and institutional discourses (Coffey \& Atkinson, 1996), such as those that were the focus of this research. Therefore, because understanding different human perspectives and life experiences was the core of this study, I chose the narrative research approach.

It is human nature for participants to be willing to narrate their stories and experiences by organizing events to help others understand their topic (Creswell, 200five). Moreover, the narrative approach allows the social life and historical periods of a specific culture and its subgroups to be deeply understood (200five). Within this context and for this study, selected Kuwaiti female leaders, as participants, narrated their stories about their personal and professional experiences as leaders.

\section{PARTICIPANTS}

For this research, I selected a number of Kuwaiti female leaders who occupied higher positions in government or non-government organizations. I defined organizations in this study as the systematic arrangement of people into groups to collaborate and plan a strategy for achieving specific goals and sharing objectives. These organizations included ministries, school districts, and social associations; they came from the business and financial sectors; and from private business. 
The research followed the narrative inquiry approach, and five participants shared their stories and experiences in depth. Participants provided information with details about events and consequences that assisted me in comprehending their perspectives through the entire analysis process.

\section{SAMPLING}

I chose a purposeful sample to meet the research objectives. This purposeful sampling provided useful information from selected participants to help with understanding the research phenomenon (Creswell, 200five). In using purposeful sampling, I chose three sampling strategies: criterion, convenience, and snowball sampling. The criterion sampling was the strategy that I chose before the data collection step; however, I used the convenience and snowball sampling strategies after I began collecting the data (200five). The criterion sampling strategy for this study can be characterized as a Kuwaiti female leader who had managed an organization that represented at least 20 employees and whose title was Minister, Vice Minister, Superintendent, Supervisor, or Manager. In addition, the other criteria were that the participant occupied a leadership position for at least 2 years, and that she understood the research phenomenon well enough to participate effectively during data collection and analysis. In addition, I used the criterion sampling strategy to select the sample from a variety of governmental and non- governmental organizations: ministerial, educational, financial, political, and social. The third strategy that I used was snowball sampling. The snowball sampling strategy took advantage of identifying other participants who were interested in the study, were willing to share their experiences with others, and at the same time met the criteria established for the sampling selection variables. With this strategy, study participants who had met the criterion and convenience sampling strategy requirements then recommended others who might also be part of the study sample (Creswell, 200five).

\section{DATA COLLECTION PROCEDURE}

I collected the data by interviewing five participants whom I selected from among Kuwaiti female leaders. The entire interviews occurred in Kuwait. The interview approach I used to meet the study criteria was the one-onone interview (Creswell, 200five). I collected the data through three interviews for each participant, and each interview typically lasted from 60 minutes to 90 minutes.

Furthermore, to meet the ethical issues that protect the participants' privacy, I changed the participants' names, I omitted their organizations' names, and I kept their identifying information anonymous. Therefore, some of the organizations that the participants worked in are unspecified and I have mentioned them only as ministries.

\section{DATA ANALYSIS AND FINDINGS}

The data analysis method that I used to represent data collection was the categorical-content perspective (Lieblich et al., 1998). The categorical-content method focuses on the entire content of data, such as the stories to be read, understood, and categorized into major themes for analysis (1998). Thus, this method was appropriate for my analysis of the stories that participants narrated by letting me break each participant's story into descriptive components to express her different experiences and various perspectives (Clandinin \& Connelly, 2000).

The first sub question was How do female leaders' culturally based personal experiences influence their leadership? Based on the data analysis, some Kuwaiti female leaders seemed to suggest that the healthy early environments in which they grew up provided a solid foundation on which to build their leadership personality. Their families raised them with principles and respectful attitudes that improved their relationships and communications with others. In addition, the support of their families, especially their parents, significantly enhanced their self-confidence, which in turn empowered their social and professional abilities within the context of their leadership responsibilities. They also described the manners and morals that they carried over into their leadership roles to respect the rules and protect others' rights. Furthermore, they transferred to their leadership style their approach from home that dealt with positive conversations, independent thinking, and lively discussions.

Within the female leaders' statements was evidence that their private lives with their husbands and children strongly affected their leadership approach. For example, some of the participants had the support and understanding 
from their spouses to pursue their ambitions to complete their education and work in job situations that were male dominated. In addition, some of the participants' fathers and husbands were open-minded in how they facilitated resolution of the life and work issues that the women faced.

In relation to personality, these females demonstrated strength, assertiveness, and confidence in dealing with their job responsibilities. They pointed out that they were capable of working beside males and deserved to be in competitive situations with them. However, they also spoke of being friendly and helpful with colleagues and other personnel, which suggests a collaborative aspect to their personalities.

Most of the females were modest in noting that their private and public personalities were consistent. Thus, their leadership personality had grown and developed within them since childhood. Moreover, they wisely balanced their social and professional relationships with employees in the respect that they were honest with them about task accomplishments and let no personal interests influence their assessments. They seemed to be altruistic regarding assisting their staff, offering guidance, and transferring personal and professional experiences to help them succeed. They also were typically more patient than their male counterparts within their job responsibilities and the objective attainment of their goals. This patience developed from their roles as housewives and mothers, which they had practiced as they managed their family responsibilities.

Hardships sometimes have a deterrent effect on people's lives. However, these Kuwaiti female leaders most of the time challenged their obstacles and faced their destiny to reach their goals. Their difficulties and barriers frequently were varied because their lives, professions, and circumstances were different; but all of them did their best to conquer these troubles efficiently.

The second research sub-question was: How do female leaders' culturally based professional experiences influence their approach to leadership? The Kuwaiti female leaders shared their professional experiences from their various jobs. Six themes evolved out of the data in response to this question. The six themes are educational environment, balancing professional and family experiences, work experiences, applying life experiences to professional life, leadership style, and lessons learned and wisdom shared.

First, the participants were concerned about their education and improving their knowledge and wisdom, for both their personal lives and their professional development. Thus, their comments demonstrate educational interest as a common theme. For most of the female leaders I interviewed, their families, parents, husbands, and siblings encouraged them to complete their education and reach a higher level of educational accomplishment.

Second, these women, in their roles as leaders, received more responsibilities, which also required more effort, over time. At the same time, they had their private life and family responsibilities that they chose to handle. Thus, they usually attempted to organize their lives to provide a balanced agenda that met all their responsibilities.

Relative to the theme of work experience, these Kuwaiti female leaders improved their status by being appointed to vital positions. They typically sought positions that met their desires and ambitions on the one hand, and proved their capabilities to manage essential organizations on the other hand. Thus, they held higher positions in different fields within governmental and non-governmental organizations.

Forth, these Kuwaiti females applied their life experiences and the valuable skills that they had gained from their life within their professions to improve their relationships with colleagues and personnel, to develop their meeting management techniques, to retain their good reputation, and in general to share their experiences with others. Furthermore, most of these female leaders felt supported by males, whether their colleagues or those in senior positions. Their experiences with males were generally beneficial; the men provided their help to ease the women's missions to become leaders, and to support them in their leadership positions. For the most part, the males also appreciated these females' endeavors and advocated for them to develop their skills and their chosen occupations.

Regarding the leadership style that each of these Kuwaiti women pursued, most clarified that each leader has an individual approach that works best with a particular organization's structure; most interacted positively with 
other personnel, and most sustained and accomplished their goals. Moreover, these female leaders often were helpful, supported their staff and met their needs, and empowered relationships that increased the development of teamwork. At the same time, they were modest and friendly with personnel and colleagues in a way that created a healthy environment. They also transferred their professional experiences, which they had gained during their attendance at formal courses and conferences, to benefit their staff.

These leaders treated their staff differently than was often customary in that they dealt individually with the various personalities and abilities. These women regularly followed a democratic leadership style and shared ideas with their staff to motivate them for productive performance. They verified that leadership means being concerned about managing personnel to work together as a team and sharing their perspectives as leaders regarding how to best accomplish tasks. Moreover, these leaders offered their clear visions and strategies that facilitated the objective to be accomplished and thus enhanced their employees' job satisfaction. In contrast, they described male leaders as more likely to be dictators who use their authority and power to carry out their responsibilities.

Last, based on their life and professional experiences, these Kuwaiti female leaders indicated that some lessons they had learned and wisdom they might share with others as advice was beneficial. Some people consider female leadership as an emotional style that might influence the situation and the decision-maker inappropriately. However, these female leaders clarified that emotions aren't necessarily a weak point that is a disadvantage of women's leadership style, but instead represent a strength that can be used to bridge the distance between leaders and workers. Some of the female leaders preferred to call the personnel they worked with by their names to create a comfortable atmosphere that increased the staff's motivation.

The female leaders were concerned about persons' equal rights to hold positions; in other words, they supported the principle of the right position for the right person, regardless of gender. Generally, these Kuwaiti female leaders demonstrated that in their experience gender didn't influence leadership as long as the leader had the required qualifications for the job. To say it differently, leaders were appointed based on their capabilities, regardless of gender preference.

In relation to the third sub-question, What new cultural experiences are female leaders gaining from their positions?, these Kuwaiti female leaders shared their perspectives about three major themes that related to the impact of culture on their personal experiences, which in turn had an impact on their leadership. The first theme pertains to cultural influences, interactions, and changes that involved female leadership in general and Kuwaitis in particular. Some participants stated that the Kuwaiti culture has changed because of the impact of other cultures. They clarified that media globalization has had its influence on the culture's norms and people's perceptions. In addition, Kuwait's different ethnic roots have also affected Kuwaitis' views regarding female leadership. The participants affirmed that religion also has had its influence on the culture's values and the customs that people practice. The female leaders explained that some religious groups were more conservative and retained their traditions and beliefs that oppose the development of women's status professionally.

The women declared that some males have had their own agenda to enhance males' control in society, which has kept females from holding positions as managers and leaders. Also, not only males who have retained their customs, but also some females and especially the elders, still hold more traditional perspectives about various issues such as female leadership and women's social interactions with males. Other Kuwaiti males, such as those in the liberal coalitions, have supported and encouraged females to improve their status and develop their leadership positions. Moreover, the Kuwaiti females who participated in this research mentioned that, in terms of cultural interactions, the cultural aspects of Kuwait have negatively influenced female leadership in terms of the gender-role. They explained that society has been mostly male dominated regarding jobs. So, over time, some families have encouraged their daughters to pursue a specific career such as teaching for its benefits, while males have controlled most essential jobs. However, some Kuwaiti females have attempted to emerge in various jobs and to hold various superior positions in both governmental and non-governmental organizations.

Furthermore, the study participants argued that Kuwaiti males have had more social relationships and a broader social network generally because they attend the Dewaneya, in which they have shared interests. So their chances to be appointed for senior positions have been higher than females' chances; and that has been one cultural 
influence that has decreased the advancement of female leadership. The women emphasized that females have often had to work harder to prove their qualifications to be appointed as seniors in organizations. So some participants recommended that qualifications and professional experiences should create the privilege that enables a person to qualify and hold a position regardless of gender, personal preferences, coalitions, intellectual orientations, or the influence of religious groups.

A second common theme that developed in the comments of these female leaders was that of gaining new experiences. They generally improved their personal, social, and professional experiences for both their individual and their organizations' benefits. They considered that learning new skills and practicing their aptitudes were vital components of their life experiences. In addition, these female leaders evaluated themselves; they attempted to discover their weaknesses and negative characteristics, and then they worked hard to improve in these areas. Moreover, these female leaders benefited not only from their coursework, but also from the exchange of experiences with their colleagues and personnel. Through their interactions with others, these women gained new, constructive experiences and enhanced their relationships with other leaders to create a dynamic atmosphere within their organizations. Simultaneously, the female leaders were concerned about increasing their communication skills and social connections with other employees and with consumers. They demonstrated that they could develop harmony and teamwork, which led to collaborative efforts and increased motivation during work to accomplish the organization's objectives. These skills helped them deal with diverse people within the organization's horizontal and vertical positions.

Finally, as the third theme that this third sub-question revealed, the Kuwaiti female leaders who participated in this research desired to transfer their life experiences for others' benefit in general, and for females in particular. So they offered advice and recommendations for both subordinate personnel and leaders. For junior personnel, these female leaders were usually concerned about how to motivate youth both personally and professionally. Moreover, the women attempted to perform as good examples and models for junior employees. As leaders, they encouraged their staff by working together as a team, making collaborative efforts, and optimistically enhancing the team spirit to attain their goals. Also, these female leaders believed they should identify others' abilities to support their advantage and help them develop other skills when needed. So these leaders often managed specialized courses and workshops that served their personnel's needs because they believed that real experiences enhanced the employees' capabilities as well as the organization's profits. Because they had gained advanced social and communication skills from their interactions, these female leaders were able to deal with various personalities, even the complicated characters; and they practiced their own personal style and techniques to treat everyone as individuals.

In support of their objectives, these women recommended that other leaders should also communicate positively with their colleagues and other administrators, and recognize how to deal with the different types of employees. They also advised other leaders to think critically before making decisions because, as leaders, biased or quick judgments might negatively influence the organization's strategy or workers' jobs. In addition, they believed that leaders should manage their organizations and acknowledge how to deal with different situations calmly and steadily.

These female leaders recommended that people in general respect the cultural norms and remain moral because society's growth started with individuals who embodied the education and principles they had learned in their homes. All these values have an impact on people's lives and situations, both personal events and professional experiences.

Regarding females' professional status, these women leaders were optimistic toward developing that status and were committed to remaining patient until they reached their goals; nothing would block or decrease their determination. They motivated other females to prove their capabilities to be appointed to higher positions. From a political view, they encouraged other women to represent themselves as candidates, and they recommended men's support during the elections. In addition, they believed social contacts and communication skills are important to improve the status of females. 


\section{DISCUSSION}

The research results suggest that there are interactions between the Kuwaiti culture, gender, and leadership. The study reflects various accumulated views and experiences about issues related to the cultural impact on gender and leadership.

Based on the participants' perspectives, the concepts and practices of Kuwaiti culture have influenced their female leadership in various ways during their personal and professional lives. Family environment had a positive impact on their female leadership. It empowered their social communications and supported the development of their personalities; it also provided a model for their performance as leaders. In addition, the traditions, customs, norms, and religions of the culture were commonly involved with developing the female leaders' personalities and character. At the same time, these female leaders influenced some aspects of the culture, including people's perspectives about the role of females as leaders. Thus, the development of female leadership within Kuwait has effectively influenced the perspectives of some people who have strengthened their beliefs in the importance of female leadership.

Additionally, these Kuwaiti female leaders developed their skills and abilities for better communication with both followers and customers. They also created their own leadership styles that respected the culture, fit with their own leaders' and subordinates' personalities, met the expectations of their organizations, and enhanced their accomplishments. And they challenged the difficulties they encountered to improve their status and enhance their achievements.

The Kuwaiti females in this study increased their status by entering, for the most part, fields that weren't open for them previously. They held higher positions as educators, doctors, and ambassadors, and in the fields of politics, economics, and business (Alsuwayeh, 198five; Tetreault, 2001). They improved their education and took advantage of opportunities to access higher institutions to increase their involvement in different organizations (Alkhaldy, 2007; Meleis, El-Sanabary, \& Beeson, 1979). In addition, their families and colleagues supported these females professionally and socially in ways that helped them to improve their skills and enhance their leadership capabilities. Moreover, the Kuwaiti female leaders tried their best to change men's negative perspectives toward their leadership. They challenged their destiny as females and attempted to rebuild their life for a bright future. Kawther Al-Joan, Seham Al-Rezouki, Dr. Rasha Al-Sabah, Dr. Fayza Al-kherafi, Dr. Masoma AlMubarak, Noreya Alsabeh, Dr. Modai Al-Hamoud, Sara Al-Duwaisan, Nabeela Alanjery, Wafa Aljassem, and Sana Jumah are just a few examples of the Kuwaiti females who have led the way for others to continue their missions as heroes in the role of female leaders.

From the perspective of breaking new ground, some of these Kuwaiti females strongly believed that their progress was increasingly being recognized and appreciated, both locally and internationally. Their achievements motivated and instilled confidence in other females to develop their own leadership behaviors to be prepared for senior positions, particularly in governmental organizations.

\section{CONCLUSION AND SIGNIFICANCE OF FINDINGS}

In conclusion, there is an influence of Kuwaiti culture on females in leadership, and this influence has two different directions. The first direction is the influence of culture on Kuwaiti female leadership. On one hand, the positive influence is the support that the Kuwaiti female leaders experience from their families, especially their male relatives such as fathers, brothers, and husbands. Also, the Kuwaiti female leaders are supported by their male colleagues because those males believe in equality of work opportunities between males and females in higher positions, and they also believe in the females' capabilities to hold such positions. On the other hand, there is a negative influence of the Kuwaiti culture on female leadership. The stereotype remains in place that women are fit for positions such as teaching but not for leadership positions in either governmental or nongovernmental organizations.

The other direction is the influence of the Kuwaiti females on the culture. These female leaders have influenced the Kuwaiti culture in different ways. First, they have positively influenced males' perspectives toward 
females as leaders. Some males now see Kuwaiti females as capable to hold higher positions in various fields. This development of female leadership in Kuwait has come with some cost. At times, female leaders experience a backlash against females in leadership from males and other females as well.

\section{RECOMMENDATIONS AND IMPLICATIONS}

In summary, the findings of this study support previous studies that highlight the influence of culture on gender and leadership (Atiyyah, 1992 \& Gibson, 199five). Different cultures have different influences on gender and leadership, as suggested by other studies. It is obvious that the Kuwaiti culture has an influence on female leadership in a distinctive way that is characterized by cultural aspects. Additional research could focus on issues related to the influence of culture on gender and leadership in either Middle East or international locations.

The aspects of the study that relate to the Kuwaiti culture should be used as positive motivation for females to improve their status and recognize that nothing can limit their ambitions to increase their contributions within society. As they developed their leadership skills, most all participants struggled with difficulties and hardships, either from their families or their male colleagues; but these circumstances couldn't prevent them from accomplishing their objectives. Similarly, other qualified females in Kuwait need to receive substantial encouragement to develop their capabilities in leadership. They also should be motivated through offers and more opportunities to lead various organizations, especially governmental organizations.

Properly preparing junior employees to develop their abilities and improve their skills to hold leadership positions could be helpful. Most participants indicated that leaders should help making significant improvement in juniors' skills and abilities by motivating them to share thoughts, attend meetings, and benefit from professional courses. Leaders should encourage the new generations by sharing with them their own strengths that might benefit the organization. It would be effective for leaders to understand junior employees' needs, ambitions, and way of thinking, and to encourage and motivate them by sharing their thoughts and ideas, and being supportive, especially during the initial period in their jobs. Also, opportunities to participate in national and international conferences that discuss leadership are, based on the current research, important for enhancing employees' experiences.

Based on the cultural norms of Kuwait, a major role for mothers is to raise their children appropriately with respect to morals and religious principles that will enable youth to fully develop their personalities as future leaders. Mothers also should naturally direct their energies toward scaffolding their children's experiences toward an intellectually stimulating future.

More acknowledgment should be focused on the organization's culture in terms of making collaborative efforts toward modifying the organizational structure and developing strategies that include female leadership for the benefit of the organization. Thus, leaders should first understand the existing organization's culture, and then evaluate and modify its strategic objectives in a way that enables the leaders to develop actions that will improve the organization's productivity and accomplish its objectives.

I suggest that future researchers might benefit from the personal and professional experiences that these Kuwaiti females gained from their work and leadership responsibilities. I also suggest that future researchers focus their efforts on issues relating to female leadership styles and the influence of culture in the context of recent developments in female leadership in Kuwait and the Middle East. So, the research question could be, how does the Middle East culture influence female leadership styles?

Future researchers also should focus on the similarities and differences between male and female leadership styles and leaders' behaviors in Arab countries, especially the Arabian Gulf and the State of Kuwait. I recommend that people learn more about female leadership styles and thus benefit from female leaders' experiences in these countries. Because this research provides results that point out the interactions of Kuwaiti culture with gender and leadership, future studies should focus on the phenomena of cross-cultural female leadership and the cultural influence on leaders' characteristics (Smith, 2006) in Arab countries. 
Another point of research should focus on conceptualizing the Kuwaiti female's accomplishment in governmental and private sectors. At the same time, evaluation and judgments of female leadership experiences in higher positions should be postponed until further female contributions in the political, social, and economic arenas have been made.

Future research could be placed on the relationships between those in leadership positions and their followers, to consider the various backgrounds of followers, the influence of this relationship on the organization's environment, and to improve these relationships. In addition, research also should pay attention to the followers who have experienced multiple leadership styles and dealt with several different leaders' behaviors. This type of study will support and improve leadership behaviors and styles for both males and females.

\section{AUTHOR INFORMATION}

Dr. Omaymah Al-Suwaihel, received Ph.D. in Educational Leadership and Human Resource Studies in 2009 from Colorado State University, the degree was granted with highest honors (GPA 4.00), and Master of Arts in Education, specialization in curriculum and instruction from Kuwait University in spring, 2004 with GPA 3.94. Dr. Al-Suwaihel has taught at several universities including Kuwait University, Arab Open University, and Colorado State University during 1994-2006. Her research concerns the Female Leadership, the Bilingual Education, the Cooperative Learning Strategy, and the Curriculum and Teaching Methods in the State of Kuwait.

\section{REFERENCES}

1. Al-Kazi, Lubna. A decades-long struggle for women's rights. Vital Voices. Retrieved April 4, 2009, from http://www.vitalvoices.org/desktopdefault.aspx?page_id=68five

2. Al-khaldy, S. (2007). The political rights for women in Kuwait legislation: Comparative political study within the international documents of human rights 1991-200five. Unpublished master's thesis. Cairo University, Egypt.

3. Al-Mughni, H. (1993). Women in Kuwait: The politics of gender. London: Saqi Books.

4. Alsuwayeh, W. (198five). The impact of culture and environment on architecture training: A needs assessment approach to designing an architecture program for Kuwait (Doctoral dissertation, The Catholic University of America, Washington, DC, 1986). Dissertation Abstracts International, 46(07), 17 five9.

5. Atiyyah, H. S. (1992). Research in Arab countries, published in Arabic. Organization Studies, 13(1), 10 five-110.

6. Cellar, D. F., Sidle, S., Goudy, K., \& O’Brien, D. (2001). Effects of leader style, leader sex, and subordinate personality on leader evaluations and future subordinate motivation. Journal of Business and Psychology, 16(1), 61-72.

7. Central Intelligence Agency, (2008). The world factbook: Kuwait. Retrieved on April 24, 2007, from https://www.cia.gov/library/publications/the-world-factbook/geos/ku.html

8. Clandinin, J., \& Connelly, M. (2000). Narrative inquiry, experience and story in qualitative research. San Francisco, CA: John Wiley \& Sons.

9. Coffey, A., \& Atkinson, P. (1996). Making sense of qualitative data. Thousand Oaks, CA: Sage Publications.

10. Creswell, J. (1998). Qualitative inquiry and research design. Thousand Oaks, CA: Sage Publications.

11. Creswell, J. (200five). Educational research: Planning, conducting, and evaluating quantitative and qualitative research. Upper Saddle River, New Jersey: Person Education.

12. Donald, J., Dale, A., \& Sonya, V. (2006). What is leadership? Journal of Veterinary Medical Education, 33(2), 280-283.

13. Gibson, C. B. (199five) An investigation of gender differences in leadership across four countries. Journal of International Business Studies, 26(2), 2fivefive-280.

14. House, R., Javidan, M., Hanges, P., \& Dorfman, P. (2002). Understanding cultures and implicit leadership theories across the globe: An introduction to project GLOBE. Journal of World Business, 37(1), 3-10.

15. Joyce, T. M. (200five). Characteristics of leadership style, sex-role, and academic culture of female leaders by institutional type (Doctoral dissertation, the State University of New York at Buffalo, 2004).

Dissertation Abstracts International, A 6five, 12, 4490. (UMI No. 31 five69five3). 
16. Kuwait Election 2006, Reformist wins elections in Kuwait and no seats for women (July 30, 2006). CNN Arabic. Retrieved April 29, 2008, from http://arabic.cnn.com/2006/kuwait.2006/6/30/kuwait.turnout/index.html

17. Lederach, J. P. (199five). Preparing for peace: Conflict transformation across cultures. Syracuse, NY: Syracuse University Press.

18. Lieblich, A., Tuval-Mashiach, R., \& Zilber, T. (1998). Narrative research, reading, analysis, and interpretation. Thousand Oaks, CA: Sage.

19. Locke, L. F., Spirduso, W., \& Silverman, S. (2000). Proposals that work: A guide for planning dissertations and grant proposals $\left(4^{\text {th }}\right.$ ed.). Thousand Oaks, CA: Sage.

20. Manning, M., \& Haddock, P. (1989). Leadership skills for women: Achieving impact as a manager. Menlo Park, CA: Crisp Publications.

21. Meleis, A., El-Sanabary, N., \& Beeson, D. (1979). Women, modernization, and education in Kuwait. Comparative Education Review, 23(1), 11five-124.

22. News analysis: Kuwait expects more harmonious politics with new Cabinet (2007, March 27). People's Daily Online. Retrieved April 18, 2007, from http://english.people.com.cn/200703/27/eng20070327_361193.html

23. Skinner, J. L. (2006). Women's pursuit of advancement opportunities: The impact of gendered climates on women's perceptions of fit with leadership (Doctoral dissertation, Northern Illinois University, DeKalb, IL, 2006). (UMI No. 3227660)

24. Smith, D. (2006). Appalachian women leaders: Product of culture and critical life events. Cypress, CA: Touro University International.

25. Tetreault, M. (2001). A state of two minds: State cultures, women, and politics in Kuwait. International Journal of Middle East Studies, 33(2), 203.

26. Thompson, M. R. (2002). Female leadership of democratic transitions in Asia. Pacific Affairs, 7 five(4), five3five-fivefivefive.

27. Weiner, A. (200five). Perceptions of leadership style as affected by gender and culture: A cross-national study (Doctoral dissertation, Alliant International University, San Diego, CA). (UMI No. 3168786) 


\section{NOTES}

